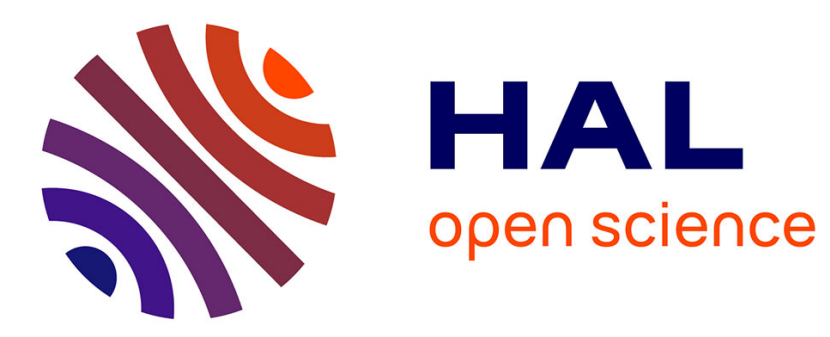

\title{
Detrusor after-contraction: a new insight
}

Françoise A Valentini, Brigitte G. Marti, Gilberte Robain, Pierre P Nelson

\section{To cite this version:}

Françoise A Valentini, Brigitte G. Marti, Gilberte Robain, Pierre P Nelson. Detrusor after-contraction: a new insight. International Brazilian Journal of Urology, 2015, 41 (3), pp.527-533. 10.1590/S16775538.IBJU.2014.0152 . hal-01270868

\section{HAL Id: hal-01270868 https://hal.sorbonne-universite.fr/hal-01270868}

Submitted on 8 Feb 2016

HAL is a multi-disciplinary open access archive for the deposit and dissemination of scientific research documents, whether they are published or not. The documents may come from teaching and research institutions in France or abroad, or from public or private research centers.
L'archive ouverte pluridisciplinaire HAL, est destinée au dépôt et à la diffusion de documents scientifiques de niveau recherche, publiés ou non, émanant des établissements d'enseignement et de recherche français ou étrangers, des laboratoires publics ou privés.

\section{(c)(1)}

Distributed under a Creative Commons Attribution| 4.0 International License 


\title{
Detrusor after-contraction: a new insight
}

\author{
Françoise A. Valentini ${ }^{1,2}$, Brigitte G. Marti ${ }^{3}$, Gilberte Robain ${ }^{1,2}$, Pierre P. Nelson ${ }^{1}$ \\ ${ }^{1}$ ER6 - Université Pierre et Marie Curie (Paris 06), Paris, France; ${ }^{2}$ Service de Rééducation Neurologique, \\ Hôpital rothschild, Paris, France; ${ }^{3}$ Service de Rééducation, Hôpital Saint Antoine, Paris, France
}

\section{ABSTRACT}

Aims: Detrusor after-contractions (DAC) are non-common in adults. Both definition (nothing in ICS reports) and significance (artefact, link with detrusor overactivity (D0) or bladder outlet obstruction (B00)) remain discussed. Our purpose was to carry out an analysis of the urodynamic parameters during voidings with DAC and, using the VBN model, to simulate pathophysiological conditions able to explain both voiding phase and DAC.

Materials and Methods: From large urodynamic database of patients referred for evaluation of lower urinary tract dysfunction, DAC were observed in 60 patients (5.7\%). Criteria for DAC were post-void residual $<30 \mathrm{~mL}$ and increase of detrusor pressure $>10 \mathrm{cmH}_{2} \mathrm{O}$. VBN model was used for analysis of both pressure and flow curves, and simulations of pathophysiological conditions.

Results: Onset of DAC (ODAC) occurred when $Q=7.3 \pm 5.7 \mathrm{~mL} / \mathrm{s}$ and bladder volume $=17.9 \pm 15.4 \mathrm{~mL}$. Urgency-frequency syndrome and urodynamic diagnosis of D0 were the more frequent scenarios associated with DAC. ODAC was associated to an inversion of the slope of detrusor pressure curve without any perturbation in flow curve. Among tested pathophysiological hypothesis (great, abnormal, detrusor force, sphincter contraction), none allowed restoring all recorded curves (flow rate, voiding pressure and DAC).

Conclusion: No urodynamic characteristic of the first part of voiding is an index of occurrence of DAC. ODAC is a significant phenomenon linked with the bladder collapse. DAC is not associated with BOO but more probably with DO and appears as the result of local conditions in an almost empty bladder (concentration of stresses around a transducer); thus DAC seems of weak clinical significance.

\section{ARTICLE INFO}

\section{Key words:}

Urodynamics; Urinary Bladder, Overactive

Int Braz J Urol. 2015; 41: 527-34

Submitted for publication:

October 07, 2013

Accepted after revision:

January 30, 2014

\section{INTRODUCTION}

Detrusor after-contraction (DAC) is an urodynamic phenomenon (Figure-1) which definition (nothing in ICS reports) $(1,2)$ is not clear despite a recent proposal as "a detrusor pressure increase after flow ceases at the end of micturition" (3) although DAC is frequently observed when the bladder is close to empty (4). The first observation by Rehflish dates from 1897, and few studies have focused on DAC; strict definition, causes and significance of that phenomenon remain far from elucidation.
Although DAC is frequently observed in children (4), it is also observed in adults. DAC is detected by all kind of pressure transducers (5). Several hypothesis about its mechanism had been suggested $(6,7)$ : DAC is an artifact or can be due to some dysfunction of the bladder or/and the urethra and thus be eventually correlated with detrusor overactivity (D0) (6) or bladder outlet obstruction (B00) (7).

Our purpose was to propose strict criteria to define DAC, then to analyze the urodynamic characteristics and to use mathematical modeling 
Figure 1 - Recording of a typical example of detrusor after-contraction (DAC) observed during intubated flow of a female patient. From top to bottom: detrusor pressure $\left(p_{\text {det }}\right)$, urethral pressure $\left(p_{\text {ura }}\right)$, vesical pressure $\left(p_{\text {ves }}\right)$, rectal pressure $\left(p_{\text {rec }}\right)$ and flow rate ( $Q$ ). Note the high amplitude of DAC compared with pdet during voiding.

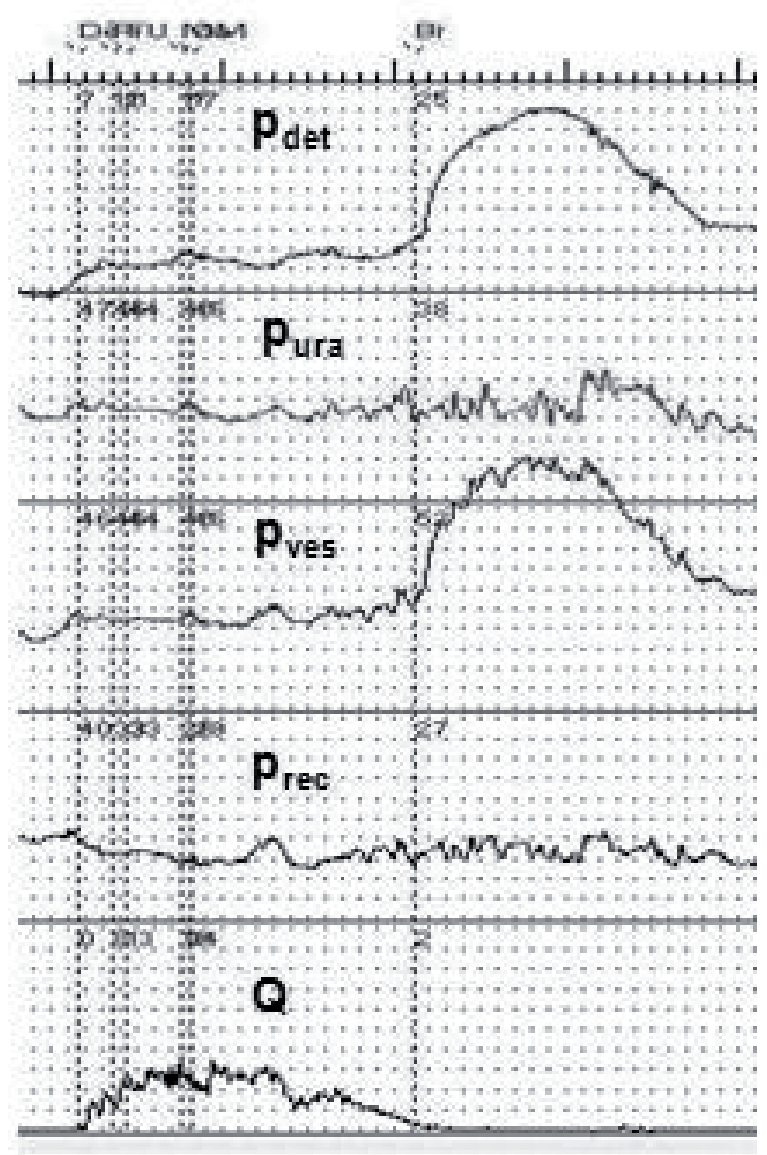

to test earlier hypotheses proposed as causes of DAC in order to answer to the question: artifact or clinical significance.

\section{MATERIALS AND METHODS}

Urodynamic recordings of patients referred to our urodynamic laboratory for evaluation of lower urinary tract dysfunction over the period January 2006 to December 2009 were retrospectively analyzed.

To state unambiguously the occurrence of DAC, two criteria were chosen: PVR should be $<30 \mathrm{~mL}$ to avoid a possible resumption of the voiding process and increase of detrusor pressure $\left(\mathrm{p}_{\text {det }}\right)>10 \mathrm{cmH}_{2} \mathrm{O}$ to avoid error of reading.

To use mathematical modeling, additional conditions were necessary for voiding phase before DAC: $Q_{\max }>2 \mathrm{~mL} / \mathrm{s}$, voided volume $\geq 100 \mathrm{~mL}$, continuous flow curves without predominant abdominal straining.

Cystometry was performed with the patient in the seated position with a 7-F triple-lumen urethral catheter perfused with saline at room temperature, using a filling rate of $50 \mathrm{~mL} /$ min. The type of catheter enabled the recording of urethral pressure during cystometry and pressure-flow study; the distal eye-hole, kept in the lateral position, was located at the site of maximal urethral closure pressure. Pressure transducers were zeroed to atmospheric pressure at the upper edge of the symphysis pubis. Rectal pressure was recorded using a punctured intra-rectal balloon catheter filled with $2 \mathrm{~mL}$ of saline according to the report of Good Urodynamic Practice guidelines (8). Post void residual volumes (PVR) were measured by ultrasound (US) using a Bladder-Scan ${ }^{\circledR}$.

Among 1823 patients who underwent filling cystometry, only 1047 succeeded (714 women and 333 men) in a pressure-flow study which fulfilled the required criteria for mathematical modeling. Among these 1047 patients and according with the proposed criteria, DAC was found in 60 patients (53 women and 7 men). Three women performed two cystometries with intubated flow in the same session, and DAC was observed in both.

\section{Method}

In a first step, careful analysis of urodynamic recordings allowed to study the urodynamic events occurring during the onset of DAC (ODAC). There was no use of mathematical modeling.

In a second step, the VBN mathematical micturition model $(9,10)$ was used to analyze the main part of the voiding phase and to test pathophysiological hypotheses able to explain the occurrence of DAC.

We recall that the VBN software, based on a global model of micturition, allows computing voiding curves: flow rate and detrusor pressure vs. 
time for any set of characteristic parameters, such as detrusor contractility, urethral parameter (compressive or constrictive), effective abdominal pressure and degree of nervous excitation of both detrusor and urethral sphincter. The model and the software are fully described in references 9 and 10 . When a good fitting between computed and recorded curves is obtained (quadratic error $<1 \%$ ), one can say that the evaluation of characteristic parameters is good. Gender, initial bladder volume and catheter geometrical obstruction are included in the model.

This study was conducted in accordance with the Declaration of Helsinki. According to the local practice of our Ethics Committee, there is no formal Institutional Review Board approval required for retrospective studies.

\section{Statistical analysis}

Data are presented as mean \pm SD and range. $t$ test, analysis of variance (ANOVA) and the chi-square test were used as appropriate. All statistical results were considered significant at $\mathrm{p}<0.05$. Statistical analyses were performed using SAS, version 5.0 (SAS Institute, Inc., Cary, NC).

\section{RESULTS}

\section{Population}

DAC occurred in $5.7 \%$ of the studied population $(60 / 1047)$ and was more frequent in women $(53 / 714=7.4 \%$ vs. $7 / 333=2.1 \%)$ than in men.

For the group with DAC, mean age was $48.4 \pm 16.4$ y [21-84 years] for women and $53.0 \pm 22.3$ years [26-79 years] for men. Nine women (16.9\%) and 2 men (28.6\%) had a history of neurological disease.

Urgency-frequency syndrome was reported by $43 / 60(71.6 \%)$ patients. Urodynamic DO was found for 32/60 (53.3\%) patients (phasic DO for 19 patients, terminal D0 for 13). Other urodynamic diagnoses were intrinsic sphincter deficiency for 13 women (11) and hypertonic sphincter for 8 women (12). B00 defined according with Abrams-Griffiths number (A-G>40) (13) for man and cut-off values $Q_{\max }<12 \mathrm{~mL} / \mathrm{s}$ and $\mathrm{p}_{\text {det.omax }}>25 \mathrm{cmH}_{2} \mathrm{O}$ for woman (14) was found in 10/60 (16.6\%) patients, respectively 1 (14.3\%) man and 9 (16.9\%) women.

\section{Characteristics of urodynamic recordings}

1- Two significant events were observed:

a- Onset of DAC (ODAC) did not occur for an empty bladder but during the latest part of flow and for a small bladder volume: $\mathrm{V}_{\text {ODAC }}=17.9 \pm 15.4 \mathrm{~mL}$ (i.e. bladder collapse condition). The ratio voided volume at the onset of DAC vs. voided volume was $0.932 \pm 0.060$. The flow rate at ODAC was $Q_{O D A C}=7.3 \pm 5.7 \mathrm{~mL} / \mathrm{s}$ (while $\left.\mathrm{Q}_{\max }=17.4 \pm 7.7 \mathrm{~mL} / \mathrm{s} ; \mathrm{p}<0.0001\right)$. Thus, $\mathrm{DAC}$ is characterized by an increase of detrusor pressure starting during the phase "return to continence" (15) of micturition; detrusor pressure reached its maximum after flow ceased in 45/60 (75.0\%) of the studied DAC.

b- In 47 (78.3\%) files, ODAC was an angular point on the pressure curve (i.e. a discontinuity of its slope with a change from negative to positive value) without disruption of the flow curve at this time (Figure-2A). Remark: the behavior of the flow curve was the same (no disruption) in absence of angular point.

2- Other urodynamics characteristics of voidings with DAC:

The pressure amplitude of DAC $\left(\mathrm{p}_{\mathrm{DAC}}\right)$ was significantly higher than $\mathrm{p}_{\text {det. } . \max }: 75.5 \pm 51.7$ vs. $34.8 \pm 18.0 \mathrm{cmH}_{2} \mathrm{O}(\mathrm{p}<0.0001)$. Voided volume was $316 \pm 145 \mathrm{~mL}$ and PVR $1.8 \pm 5.4 \mathrm{~mL}$.

Urethral behavior could not be assessed in 13 files because the transducer moved (leveling of both urethral and vesical pressures). No change of activity of urethra was observed in 21/47 (44.7\%) files. An increase of rectal pressure was observed at ODAC in $8 / 60(13.3 \%)$ files $\left(20.1 \pm 10.6 \mathrm{cmH}_{2} \mathrm{O}\right)$ but with concomitant increase of urethral pressure in only 1 file. No change of rectal activity has been observed in the 52 remaining files.

No change of activity of both urethra and rectum in 17/47 (36.2\%) was observed during DAC.

\section{3- Patterns of DAC}

Assessment of patterns of DAC was made according with the description of Ruarte et al. (4). Among the more simple patterns, 30 bell shaped curves, 5 with small waves during the rising phase and 4 of high amplitude and tower shape were 
found. Other patterns were more complicated: 11 irregular and prolonged, 6 with sharp peak in the rising phase, 4 two headed and 2 with fluctuations in the falling phase. Whatever the pattern of DAC (4), the increase in $p_{\text {det }}$ was not associated to any change in flow rate.

Looking at the three files with 2 DAC, the 2 DAC exhibited a difference in shape, pressure and duration.

VBN analysis of voidings with DAC and simulation of pathophysiological conditions

For each patient the voiding phase until the onset of DAC was restored by VBN analysis (Figures 2 A-D). As in voiding without DAC, the fitting of recorded and computed curves in the terminal part was sometimes obtained with the addition of an effective abdominal pressure (which only acts on the bladder) in 30/60 (50\%) files (Figures 2 C-D). That additional pressure clearly began before the onset of DAC (Figures 2 C-D).

After the onset of DAC, the flow curve was restored using the same VBN mechanical parameters (detrusor force and urethral parameter) as in the initial phase of voiding. But we did not succeed to restore the slope of the increase of $p_{\text {det }}$ and its maximum value with these parameters.

Tested hypothesis to restore DAC were to introduce in the computation a strong sphincter excitation or a great (abnormal) detrusor force starting during that last phase of micturition. None of these hypotheses enabled us to restore the whole recorded curves (flow rate, detrusor pressure including DAC). More, the VBN model or any global model of micturition could not explain the brisk change in the slope of the detrusor pressure curve without any flow perturbation (Figure 2-A).

\section{DISCUSSION}

From analysis of urodynamic recordings of micturition with DAC, we propose the following definition of DAC: a detrusor pressure increase (higher than $10 \mathrm{cmH}_{2} \mathrm{O}$ to avoid artifact of interpretation) during the phase "return to continence" of micturition (15) with PVR less than $30 \mathrm{~mL}$ (to avoid confusion with reinforcement of detrusor pressure to empty the bladder).
If reference to a limit in detrusor pressure is usually mentioned in the studies on DAC (16) there is a lack of information about the $\operatorname{PVR}(4,7)$.

In the studied adult population, prevalence of DAC is $5.7 \%$ which is in the range of the results of Webster et al. (17) and Cho et al. (7) who respectively found a prevalence of 2.0\% and 8.1\%.

Significance of DAC is often discussed. In their study in children with non-neurogenic incontinence problems, Hoebeke et al. (18) concluded that DAC were indicators of detrusor instability. In adults, D'Amico et al. (6) found a statistical correlation among DAC and detrusor overactivity (DO) and overactive bladder (OAB), Cho et al. (7) concluded that DAC was significantly correlated to the presence of BOO. in our study (only adult individuals), urgency-frequency syndrome and urodynamic diagnosis of DO are the more frequent scenarios associated with DAC, B00 is less frequent than DO. But the liability of the correlations is weak.

For all the studied urodynamic recordings, flow and pressure curves before ODAC are successfully analyzed using the standard VBN model: the first part of voiding does not possess any characteristic that could predict the occurrence of DAC.

Close to emptying $(\mathrm{V}<40 \mathrm{~mL})$ the bladder collapses and becomes flat or wrinkled while its shape is close to be spherical when filled. While at ODAC, the flow rate is still $0.42 \mathrm{Q}_{\max }$, the bladder volume is close to the condition of bladder collapse $\left(\mathrm{V}_{\text {ODAC }}=17.9 \pm 15.4 \mathrm{~mL}\right)$. We conclude that $\mathrm{DAC}$ is related in some way with collapse.

The flow rate before and after ODAC obeys the standard VBN model without any change in the parameters value; this is not the case of the detrusor pressure. Two kinds of explanations can be considered. Either the recorded pressure is not the real detrusor pressure, but is an artifact, or the voiding phase during DAC results from a brisk change of the voiding parameters. That second mechanism has been proposed by RL Vereecken (19) who performed needle EMG and concluded that DAC "is only the expression of a sphincter contraction interrupting an incomplete detrusor contraction", i.e. "a late dyssynergic urethral sphincter contraction”. 
Figure 2 - Four examples of VBN analysis of voidings followed by detrusor after-contraction (DAC) in female patients. The description only concerns the lower register (flow and pressures): $\mathbf{Q}$ (recd) (red)= recorded $\mathbf{Q} ; \mathbf{Q}$ (comp) (blue)= computed $\mathbf{Q}$; $p_{\text {det }}\left(\right.$ recd) (fuchsia) $=$ recorded $p_{\text {det }} ; p_{\text {det }}($ comp $)($ grey $)=$ computed $p_{\text {det }} ; p_{\text {abd.eff }}\left(\right.$ comp) $($ green $)=$ computed $p_{\text {abd.eff }}$.
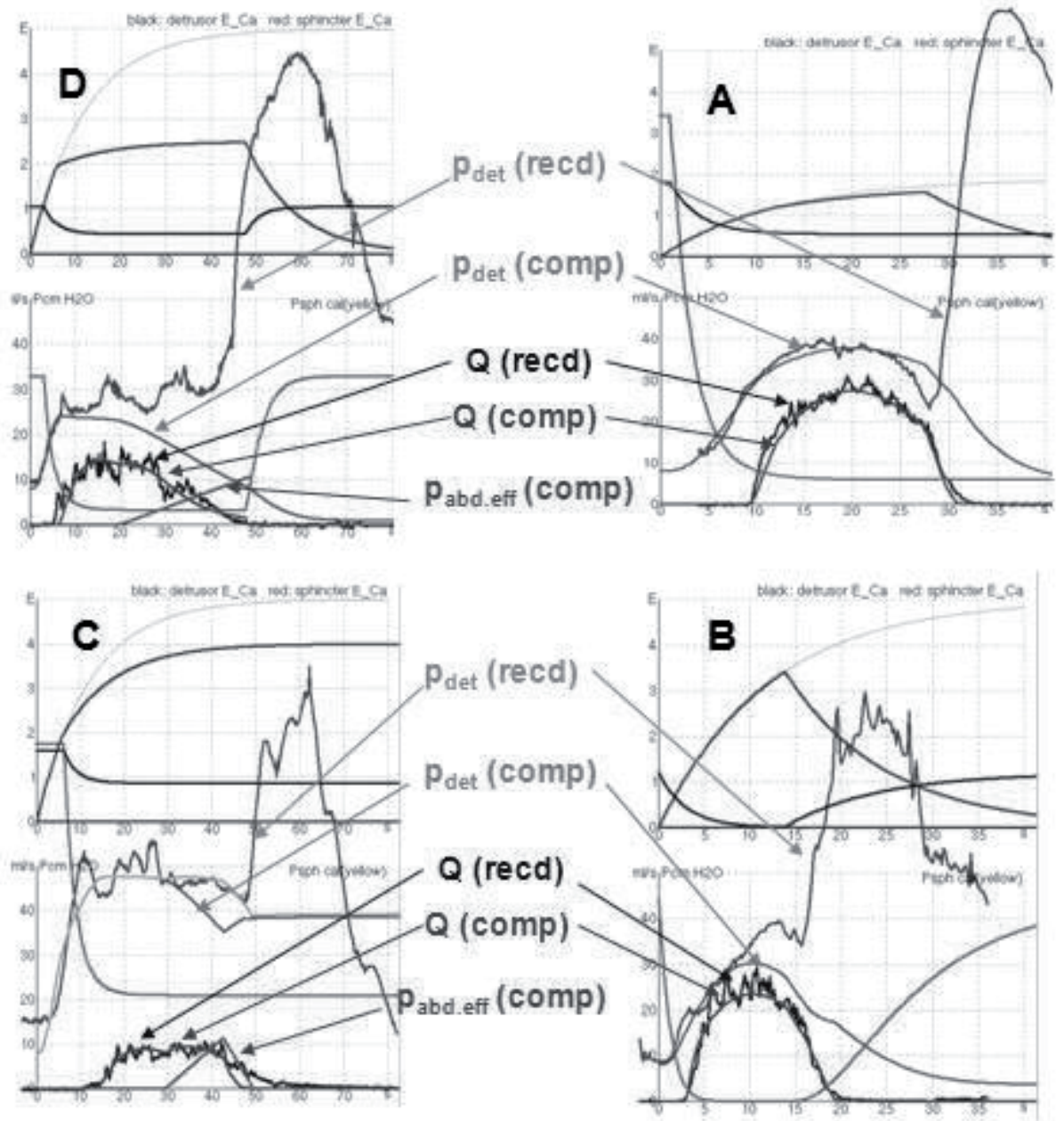

In the lower register, the yellow curve (A-D) without label is the computed sphincter pressure, and the cyan curve (C) the sum computed $p_{\text {det }}$ plus computed $p_{\text {abdefft }}$ A) A very impressive brisk increase of pdet at the onset of DAC.

$C, D$ : additional effective abdominal pressure $\left(\mathrm{p}_{\text {abdeff }}\right)$ which only acts on the bladder to achieve emptying. That additional pressure clearly begins before the onset of DAC.

In the upper register of each analysis: computed detrusor and sphincter excitations (for details about the VBN model, see references 9,10 ).

It has been shown that large PVR or/and decreased maximum flow rate during intubated flow without DAC can be the consequence of a compression-like effect possibly due to an urethral reflex induced by the catheter in situ $(20,21)$.

So, the Vereecken hypothesis is realistic and we have tested it. Starting from the VBN analysis of the first part of a voiding with DAC, a strong sphincter excitation is introduced in the computation at the time of ODAC. The result is an insufficient increase of detrusor pressure and arrest of the flow.

More generally, whatever the change in mechanical parameter tested (sphincter contraction or/and increased detrusor force, effective abdominal pressure only acting on the bladder) we 
never succeeded to reproduce simultaneously the flow curve, both slope and amplitude of the recorded pressure and still less the discontinuity of the slope at ODAC. Thus the artifact hypothesis must be reconsidered.

Some authors asserted that DAC is a possible artifact related to recording during the final phase of micturition (22). In this study, despite a small number of patients, when DAC is observed during two successive intubated flows, DACs differ in all characteristics. Two papers advocated the hypothesis that the sensible membrane of a microtip transducer could be pressed against the wall of the empty bladder and falsely record an increase in detrusor pressure $(22,23)$. From our analysis we agree with these last assumptions.

A plausible explanation is that in most cases, at the end of voiding, the transducer shifts on a smooth bladder wall which does not create any pressure but that in some cases, the transducer is trapped in a bladder fold which leads to a local concentration of stresses and induces the observed increase in pressure. That last condition can explain the brisk change in the slope of $p_{\text {det }}$ curve without any change in the flow curve. Why the DAC stops remains not understood. A hypothesis is that the stresses exerted by the bladder wall on the tip of the catheter are sufficient to expel the catheter from the bladder fold.

Limitations of our study include the fact that it is retrospective, and that EMG and video-urodynamics are not used. We don't routinely use EMG because needle EMG which gives the best information increases the invasiveness. Video-urodynamics would be informative if the location of the transducer could be clearly identified on the pictures; as it is not the case, mainly when the bladder is close to collapse condition, its usefulness remains discussed.

\section{CONCLUSIONS}

No urodynamic characteristic of the first part of voiding is an index of occurrence of DAC. The onset of DAC is a significant phenomenon which is linked with the bladder collapse. During a voiding with DAC, the flow rate obeys a global model of micturition while the detrusor pressu- re obeys the model only until the onset of DAC; DAC pressure cannot be restored using this model. Thus, DAC appears to be more probably an artifact. The interaction of the transducer with the bladder wall leads to a concentration of stresses around the transducer similar to that observed at the tip of a nail. DAC appears as the result of local conditions in an almost empty bladder and thus of weak clinical significance.

\section{ABBREVIATIONS}

$\mathrm{A}-\mathrm{G}=$ Abrams-Griffiths number

$\mathrm{BOO}=$ Bladder outlet obstruction

DAC $=$ Detrusor after-contraction

DO $=$ Detrusor overactivity

EMG = Electromyography

ICS = International Continence Society

ODAC $=$ Onset of detrusor after-contraction

$\mathrm{p}_{\text {det }}, \mathbf{p}_{\text {det. Omax }}=$ Detrusor pressure, detrusor pressure at maximum flow rate

$\mathrm{p}_{\mathrm{DAC}}=$ Pressure amplitude of detrusor after-contraction

PVR $=$ Post void residual volume

$Q, Q_{\max }=$ Flow rate, maximum flow rate

US = Ultra sound

VBN = Valentini-Besson-Nelson (authors name)

\section{ACKNOWLEDGEMENTS}

The authors thank Mrs. Charlotte Marti (ISIT-Master 1CIT) for her help in the translation of this article.

\section{CONFLICT OF INTEREST}

None declared.

\section{REFERENCES}

1. Abrams P, Blaivas JG, Stanton SL, Andersen JT. The standardisation of terminology of lower urinary tract function. The International Continence Society Committee on Standardisation of Terminology. Scand J Urol Nephrol Suppl. 1988;114:5-19. 
2. Abrams P, Cardozo L, Fall M, Griffiths D, Rosier P, Ulmsten $\mathrm{U}$, et al. The standardisation of terminology of lower urinary tract function: report from the Standardisation Sub-committee of the International Continence Society. Neurourol Urodyn. 2002;21:167-78.

3. Hogan S, Gammie A, Abrams P. Urodynamic features and artefacts. Neurourol Urodyn. 2012;31:1104-17.

4. Ruarte AC, Podestá ML, Medel R. Detrusor aftercontractions in children with normal urinary tracts. BJU Int. 2002;90:286-93

5. Bors E, Commar AE. Micturition. In Bors E, Commar AE eds Neurological Urology, Chapt II, Basel: S. Karger. 1971:31-60.

6. D'Amico A, Pesce F, Rubilotta E, Sarti A, Curti P, Artibani W. Correlation between detrusor after-contraction and overactive bladder syndrome, detrusor overactivity and post micturition dribble. Neurourol Urodyn 2003;22:457-8.

7. Cho SY, Yi JS, Park JH, Jeong MS, Oh SJ. Detrusor aftercontraction is associated with bladder outlet obstruction. Neurourol Urodyn. 2011;30:1361-5.

8. Schäfer $W$, Abrams $P$, Liao L, Mattiasson A, Pesce F, Spangberg A, et al. Good urodynamic practices: uroflowmetry, filling cystometry, and pressure-flow studies. Neurourol Urodyn. 2002;21:261-74.

9. Valentini FA, Besson GR, Nelson PP, Zimmern PE. Clinically relevant modeling of urodynamics function: the VBN model. Neurourol Urodyn. 2014;33:361-6.

10. Valentini FA, Besson GR, Nelson PP, Zimmern PE. A mathematical micturition model to restore simple flow recordings in healthy and symptomatic individuals and enhance uroflow interpretation. Neurourol Urodyn. 2000:19:153-76.

11. Constantinou CE Urethrometry. Considerations of static, dynamic, and stability characteristics of the female urethra. Neurourol Urodyn 1988;7:521-39.

12. Zermann D-H, Ishigooka M, Schmidt RA. Pathophysiology of the hypertonic sphincter and hyperpathic urethra. In Corcos J, Schick E eds. The urinary sphincter, Chapt 13, New York, Basel: M. Dekker Inc. 2001:201-21.

13. Lim CS, Abrams P. The Abrams-Griffiths nomogram. World J Urol. 1995; 13: 34-9.

14. Defreitas GA, Zimmern PE, Lemack GE, Shariat SF. Refining diagnosis of anatomic female bladder outlet obstruction: comparison of pressure-flow study parameters in clinically obstructed women with those of normal controls. Urology. 2004;64:675-9; discussion 679-81.
15. Valentini FA, Mazières L, Nelson PP. Can modeled analysis of urodynamic recordings help to demonstrate the nervous control of the bladder and urethra during micturition ? UroToday Int J. 2010;3 August.

16. Pesce F, Rubilotta E. Detrusor after-contraction: is this important? Curr Urol Rep. 2004;5:353-8.

17. Webster GD, Koefoot RB, Zakrewski JB, Todd S. The aftercontraction in urodynamic micturition studies. Neurourol Urodyn 1983;2:213-8.

18. Hoebeke PB, Van Gool JD, Van Laecke E, Vande Walle J, Plancke $\mathrm{H}$. The after-contraction in paediatric urodynamics. Br J Urol. 1996; 78: 780-2

19. Vereecken RL. The after-contraction: a true detrusor contraction or a late dyssynergic urethral sphincter contraction? BJU Int. 2000;85:246-8.

20. Valentini F, Marti B, Robain G, Nelson P. Differences between the data from free flow and intubated flow in women with urinary incontinence. What do they mean? Neurourol Urodyn. 2008;27:297-300.

21. Valentini FA, Robain G, Hennebelle DS, Nelson PP. Decreased maximum flow rate during intubated flow is not only due to urethral catheter in situ. Int Urogynecol J. 2013;24:461-7.

22. van Dongen $\mathrm{E}$, Bemelmans B, Heesakkers J. After contraction of the bladder: of no pathological significance? 32nd Annual Meeting of the International Continence Society, Heidelberg, Germany August 28-30, 2002. Abstract \# 178.

23. Mutchnik SE, Sukin S, Boone TB. Case studies in voiding dysfunction. Contemp Urol Arch 1999; 110-3.
Correspondence address:

Françoise A. Valentini, MD, PhD Service de Rééducation Neurologique, Hôpital rothschild, 5, rue Santerre, 75012, Paris, France Fax: +33 1 4019-3656 E-mail: favalentini@gmail.com 


\section{EDITORIAL COMMENT}

DAC is not a common finding in urodynamics evaluation, and is a phenomenon with no clear definition even in the ICS.

In ancient times it was a common belief that urodynamics must reproduce the patient's complain to be of any value. Following this statement, we hardly try to find involuntary detrusor contractions in patients with reliable reports of urge incontinence. We did not had the clear knowledge that, for instance, more than half patients with $\mathrm{OAB}$ would not show involuntary bladder contraction during cistometry.

By that time, DAC worth as something to report in a patient with urgency and a normal cistometry, and this finding was also associated with BOO.

In this paper, the authors analyzed 60 urodynamic evaluations with DAC, and although DO were associated with this finding, they did not find a strong clinical significance for this finding.
Is DAC a true detrusor contraction or a late dyssynergic urethral sphincter contraction or an artifact? It cans be everything, but I do agree that this phenomena in more an artifact. The proposition for further studies with EMG and video urodynamics to clarify our doubts is worthy, but its clinical usefulness perhaps will be little.

From this paper, we can give to DAC its true value: weak clinical significance.

\section{REFERENCES}

1. Vereecken RL. The after-contraction: a true detrusor contraction or a late dyssynergic urethral sphincter contraction? BJU Int. 2000;85:246-8.

2. Pesce F, Rubilotta E. Detrusor after-contraction: is this important? Curr Urol Rep. 2004;5:353-8.

Alfredo Canalini, $M D$ Titular da Sociedade Brasileira de Urologia Member of the American Urological Association Member of the European Urological Association 